\title{
The first bulk nanostructured metal
}

\author{
H K D H Bhadeshia \\ University of Cambridge, Materials Science and Metallurgy, Cambridge, UK \\ E-mail: hkdb@cam.ac.uk
}

Received 23 October 2012

Accepted for publication 28 November 2012

Published 11 March 2013

Online at stacks.iop.org/STAM/14/014202

\begin{abstract}
Nanotechnology has become an overused adjective, but there has been justified excitement in the context of structural materials. A class of iron alloys has been discovered in which a high density of strong interfaces can be created by heat-treatment alone. The packing of interfaces is so large, and the fact that there is an intrinsic work hardening mechanism in the structure, leads to remarkable properties. The genesis of this structure, its commercialization, the new science associated with the discovery, and its limitations are all explored in this short review.
\end{abstract}

Keywords: nanostructured, steel, bainite, phase transformation, alloy design

\section{Introduction}

Nanostructured structural-materials are the fashion of the day, but to take the concept to a point where it can be exploited commercially has until recently been impossible. The purpose of this review is to describe the process that led to the creation of a practically useful nanostructured engineering alloy. We first set the scene by describing the origins of strength and why a refinement of crystal size in such a material is important.

One of the basic tenets of metallurgy is that disruptions in the orderly arrangement of atoms lead to strengthening as long as the temperature and time-scales of the experiment are sufficiently small to prevent the diffusion of atoms. Single crystals can therefore be strengthened by introducing foreign atoms that form solutions which are not ideal from a thermodynamic point of view, or by the presence of high-entropy defects such as vacancies or self-interstitials. Other more macroscopic defects such as stacking faults and dislocations serve the same purpose. The volume of the single crystal influences its strength when it becomes comparable to the volume per defect. This is because it is more likely that a small crystal can be perfect; the deformation of a perfect crystal requires a coordinated movement of large numbers of atoms, whereas the propagation of localized disturbances permits the easy slip of imperfect crystals [1]. The shape of a single crystal may also correlate with strength because many of the intrinsic properties of all crystals, such as the elastic modulus and magnetization, are anisotropic.

Content from this work may be used under the terms of the Creative Commons Attribution-NonCommercial-ShareAlike 3.0 licence. Any further distribution of this work must maintain attribution to the author(s) and the title of the work, journal citation and DOI.
Additional degrees of freedom are introduced when identical crystals form polycrystalline aggregates. Both the orientation of the resulting grain boundaries, and the relative orientations of the crystals that they connect, can then be varied independently. These boundaries not only provide barriers to the motion of dislocations but in ductile materials, their presence requires that each crystal must be able to slip on at least five independent slip systems, thus greatly increasing the work hardening accompanying plastic deformation.

The next stage of complexity comes when the objects within a polycrystalline material are of different crystal structure. It then becomes more difficult to define the nature of the grain boundaries and their ability to obstruct the flow of matter. Such boundaries are often referred to as interphase interfaces and they should in general be more formidable obstacles to dislocation motion. This is illustrated by the fact that grain boundaries can be eliminated by a rigid-body rotation of one crystal relative to the other, whereas a more general deformation is required to achieve the same effect for interphase interfaces [2,3]. The mixture of phases can be in the form of fine precipitates dispersed in a matrix, or as multiple phases, each of which comprises a fair proportion of the overall structure.

The dependence of strength on grain size is often expressed in terms of the Hall-Petch equation [4, 5] for equiaxed structures, and a different dependence for thin plate shaped grains $[6,7]$. In the first case the strength depends on $\bar{L}^{-1 / 2}$ and in the second on $\bar{L}^{-1}$ where $\bar{L}$ is the mean lineal intercept as a measure of the effective grain size. Not only is strength affected by refining $\bar{L}$, but so is the distance across which a brittle crack may propagate unhindered. 
Table 1. The surface per unit volume $\left(S_{V}\right)$ associated with a variety of steel based structures. The terms $t, r$ and $N_{V}$ refer to the true plate thickness, precipitate radius and number density per unit volume, respectively. The strength values $(\sigma)$ quoted are for ambient temperature and are approximate, often estimated from hardness or microhardness.

\begin{tabular}{llllc}
\hline Structure & & Parameters & $S_{V}\left(\mathrm{~nm}^{-1}\right)$ & $\sigma(\mathrm{MPa})$ \\
\hline Nanostructured bainite & {$[13]$} & $t=20-40 \mathrm{~nm}$ & $2 t^{-1}=0.10-0.05$ & $>2100$ \\
Mechanical milling & {$[14]$} & $\bar{L}=20 \mathrm{~nm}$ & $2 \bar{L}^{-1}=0.1$ & 2850 \\
'Nanobainite' & {$[15]$} & $\bar{L}=200-400 \mathrm{~nm}$ & $2 \bar{L}^{-1}=0.005-0.01$ & $<960 \mathrm{MPa}$ \\
Nanoparticle strengthened & {$[16]$} & $N_{V}=1.1 \times 10^{24} \mathrm{~m}^{-3}, r=1.25 \mathrm{~nm}$ & $4 \pi r^{2} N_{V}=0.011$ & 800 \\
Accumulative roll bonding & {$[17]$} & $\bar{L}=420 \mathrm{~nm}$ & $2 \bar{L}^{-1}=0.005$ & 870 \\
Severe plastic deformation & {$[18]$} & $\bar{L}=100 \mathrm{~nm}$ & $2 \bar{L}^{-1}=0.02$ & 1570 \\
Angular processing & {$[19]$} & $\bar{L}=200 \mathrm{~nm}$ & $2 \bar{L}^{-1}=0.01$ & 1150 \\
\hline
\end{tabular}

Therefore, unlike many other mechanisms of making strong materials, grain boundaries simultaneously strengthen and toughen polycrystalline materials, where toughness refers to the ability of the material to absorb energy during fracture.

It is possible also for one or more of the phases to undergo transformation into an alternative structure during deformation. If this happens to create a stronger phase then the work hardening rate can be enhanced. Transformation induced plasticity (TRIP) steels are a classical example of how deformation by moving interfaces [8] leads to greater ductility by delaying the onset of plastic instability (necking) during tensile testing [9].

It is in the context of this basic knowledge about strength that intense activity started some 15 years ago to progress from the tremendous success of thermomechanically processed microalloyed steels where the grain sizes achieved in billions on tonnes of materials routinely reach $10 \mu \mathrm{m}$ $[10,11]$, and occasionally approach $1 \mu \mathrm{m}$ [12]. It was logical, therefore, to aim for even smaller grain size in the hope of fuelling the next generation of strong and tough steels that can be mass produced.

\section{Nanostructure}

The term 'nanostructure' has unfortunately become a generic reference to a wide range of grain and precipitate structures. For present purposes it is defined to represent cases where the interfacial area per unit volume, $S_{V}$, is large enough to make the governing length scale $\bar{L}=2 / S_{V}$ comparable to the dimensions of carbon nanotubes, i.e., of the order $20-50 \mathrm{~nm}$. There is logic behind this definition, as illustrated by the data in table 1 . Thus, a coarse-grained structure containing nanoparticles, or a structure referred to as nanobainite but which has a scale closer to micrometres does not have a large $S_{V}$ and hence is not strong. Figure 1 shows that the amount of surface per unit volume only becomes sensitive to the grain size when the latter is below about $50 \mathrm{~nm}$.

\section{Design}

There are formidable difficulties in creating novel nanostructures which have the combination of properties appropriate for large-scale applications [20]. Severe deformation including mechanical milling, equal channel angular processing and high-pressure torsional straining have

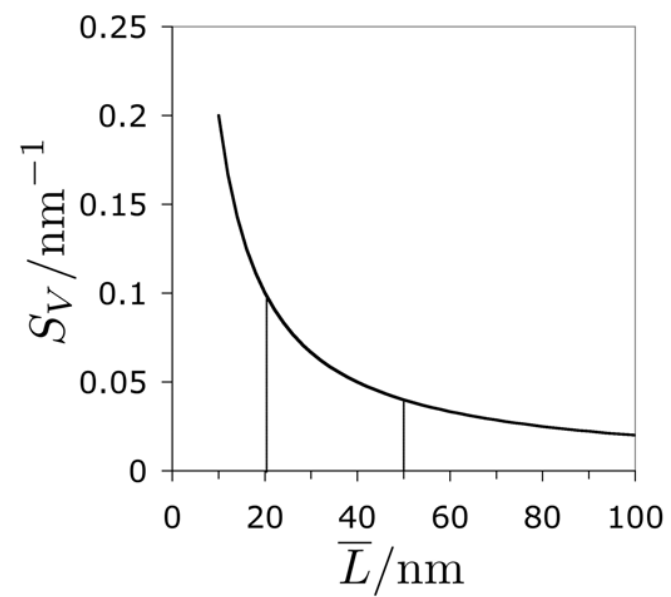

Figure 1. Grain surface per unit volume as a function of the mean lineal intercept, a measure of the grain size.

not succeeded in this respect. Martensitic transformation can produce the fine structures but require either rapid cooling or large concentrations of substitutional solutes in order to through-harden components. Based on the above discussion, it is necessary to define some design criteria which, if not satisfied, would render the material only of academic interest [20, 21]:

1. It should ideally be possible to manufacture components which are large in all dimensions, not simply in the form of wires or thin sheets.

2. There are commercially available steels in which the distance between interfaces is of the order of $250-100 \mathrm{~nm}$. The novelty is in approaching a structural scale in polycrystalline metals that is an order of magnitude smaller.

3. The material concerned must be cheap to produce if it is not to be limited to niche applications. A good standard for an affordable material is that its cost must be similar to that of bottled water when considering weight or volume.

All of these conditions can in principle be met by the phase transformation of austenite into bainite, partly because the reaction is particularly amenable to control by either isothermal or continuous cooling heat treatment. Furthermore, the transformation is displacive, i.e., it leads to a shape deformation which is macroscopically an invariant plane strain with a large shear component, as illustrated in figure 2. 


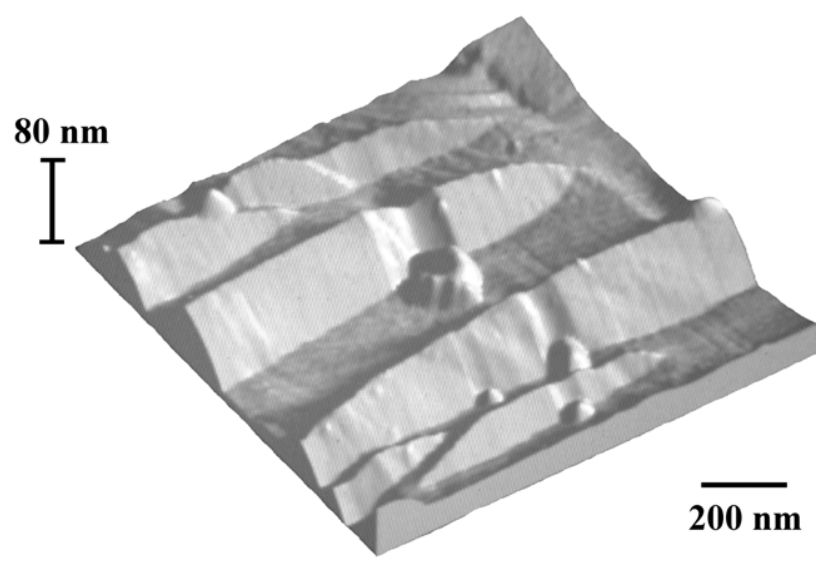

Figure 2. A sample of steel polished flat, austenitized and then transformed into bainitic ferrite, resulting in large upheavals of the surface, representing a shear strain of $\approx 0.46$ and a dilatational strain normal to the habit plane of 0.03 [22].

In order to minimize strain energy, the product is therefore in the form of thin plates, which, because they are lengthy, have a mean free slip distance of only twice the thickness. In other words, the grain size is related to the thickness rather than the length.

It has been known that the platelets of bainite become thinner as the transformation temperature is reduced, and modern analysis confirms this [23, 24]. What then is the lowest temperature at which bainite can be generated? The lower limit must represent the martensite start temperature, so the answer lies in suppressing both the bainite and martensite start temperatures, and it is necessary to resort to detailed calculations. The atomic mechanism of the bainite reaction is not yet fully understood or appreciated [25] but, as demonstrated in a compendium ${ }^{1}$, there has been sufficient progress to enable the quantitative design of useful steels.

The highest temperature at which bainite can form in a steel of fixed composition is known as the bainite start temperature $\left(B_{\mathrm{S}}\right)$, and the corresponding temperature for martensite, $M_{\mathrm{S}}$, is similarly defined. The theory determining these start temperatures has been described elsewhere [26-28]. Figure 3(a) shows, for an example steel, how the $B_{\mathrm{S}}$ and $M_{\mathrm{S}}$ temperatures vary as a function of the carbon concentration. There appears to be no lower limit to the temperature at which bainite can be generated. On the other hand, the rate at which bainite forms slows down dramatically as the transformation temperature is reduced (figure 3(b)). It may take hundreds or thousands of years to generate bainite at room temperature. For practical purposes, a transformation time of tens of days is reasonable, corresponding to a carbon concentration of about $1 \mathrm{wt} \%$, in which case bainite can be generated at a temperature as low as $125^{\circ} \mathrm{C}$, which is so low that the diffusion distance of an iron atom is an inconceivable $10^{-17} \mathrm{~m}$ over the time scale of the experiment. Diffusion of iron is not of course necessary since the transformation is displacive.

A steel designed on this basis was manufactured and characterized [13, 30, 31]; figure 4 shows the structure

\footnotetext{
1 Special issue of 2004 Curr. Opin. Solid State Mater. Sci. 8 211-311.
}

obtained following isothermal transformation at $200{ }^{\circ} \mathrm{C}$, consisting of platelets of bainitic ferrite only 200-400 thick, with intervening regions of the parent austenite $(\gamma)$. This retained austenite is important because when it undergoes stress or strain-induced martensitic transformation, it enhances the work-hardening capacity of the material, thereby avoiding the usual problem of fine-grained metals where ductility diminishes as the grain size is reduced $[32,33]$. Since the original work, many variations of the alloy have been studied and the structure has been characterized, both chemically and spatially to an atomic resolution. The details are described elsewhere [20, 34], but it is important to note that the material is now fully commercialized [35] and can be bought in the thousands of tonnes. Some photographs of the commercial product are given in figure 5. The strength can be as high as $2.5 \mathrm{GPa}$ [20] with excellent combinations of strength, ductility [36-38], toughness [20, 39, 40], fatigue resistance [41, 42] and wear resistance [43, 44]; some of the properties are displayed in figure 6. There have even been powder metallurgical variants where a strength of some $1800 \mathrm{MPa}$ and a ductility of about $6 \%$ is obtained in spite of an oxygen content of $0.23 \mathrm{wt} \%$ [45].

The story of the bulk nanostructured steel goes beyond the process of design and commercialization; the work has stimulated a large amount of academic and industrial research, some of which has had a profound influence on the subject. The outcomes up to the year 2010 have already been reviewed [20], so the focus below is on some new discoveries since then.

\section{Excess carbon in bainitic ferrite}

The maximum solubility of carbon in ferrite that is in equilibrium with austenite is a little greater than $0.02 \mathrm{wt} \%$ at a temperature of about $600{ }^{\circ} \mathrm{C}$ due to the retrograde shape of the $\alpha / \alpha+\gamma$ phase boundary [47, 48]. It has been known in this context that bainitic ferrite is supersaturated with an excess of carbon [49-52]. This carbon fails to partition into the residual austenite in spite of the fact that the process is not limited by atomic mobility [53]. In fact, the accumulated evidence demonstrates that the carbon inherited by bainitic ferrite is reluctant to partition into the residual austenite in spite of prolonged heat treatment [49, 54-58]. The early interpretations of these observations attributed the reluctance of the carbon to partition on the presence of dislocations which trap the solute. However, recent work has shown conclusively using the atom-probe technique that large quantities of excess carbon remain in defect-free solid solution [59, 60].

A possible explanation is that the tetragonality caused by the presence of carbon changes the equilibrium between austenite and body-centred cubic ferrite [61]. Since the symmetry of the ferrite is changed, thermodynamic data were calculated using $a b$ initio methods, and subsequently incorporated into phase diagram calculations. The results are shown in figure 7 where it is clear that the solubility of carbon in tetragonal ferrite in equilibrium with austenite is much larger that that for cubic ferrite. 


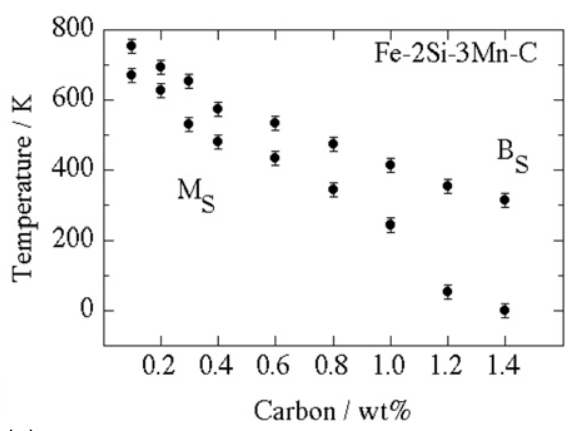

(a)

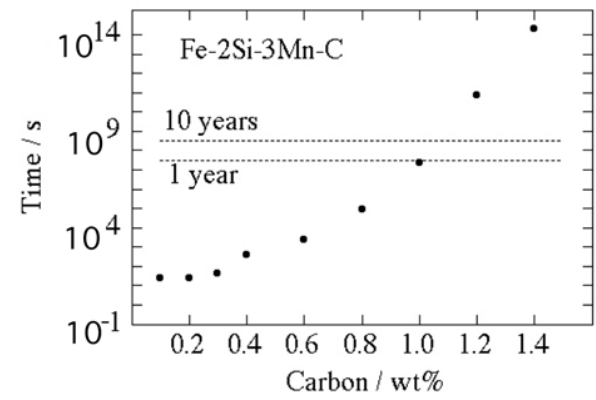

(b)

Figure 3. (a) Calculated transformation start temperatures in $\mathrm{Fe}-2 \mathrm{Si}-3 \mathrm{Mn}$ steel as a function of the carbon concentration. (b) The calculated time required to initiate bainite [29].

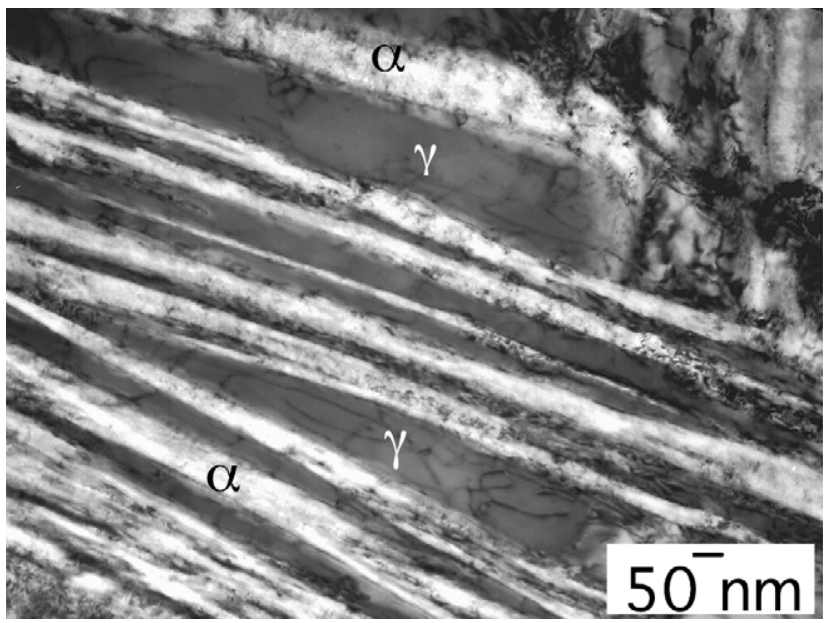

Figure 4. $\mathrm{Fe}-0.98 \mathrm{C}-1.46 \mathrm{Si}-1.89 \mathrm{Mn}-0.26 \mathrm{Mo}-1.26 \mathrm{Cr}-0.09 \mathrm{~V}$ wt $\%$, transformed at $200{ }^{\circ} \mathrm{C}$ for 15 days. Bright field transmission electron micrograph $[13,30,31]$.

It is possible therefore that the change in symmetry of the ferrite may explain the observed reluctance for the 'excess' carbon present in bainitic ferrite to partition into the residual austenite despite prolonged heat treatment. The tetragonality may exist over a long range, but the possibility of a domain structure such as that found in minerals which undergo cubic to tetragonal transitions, should not be ruled out.

\section{Consequences on the mechanism of transformation}

The frenzy of activity that followed the discovery of nanostructured bainite has in some cases revealed vital information about the choreography of atoms during the transformation:

1. It is now clear that the crystallography of the low-temperature bainite platelets is such that there is an exceptionally large shear strain of $\approx 0.46$ accompanying transformation [22], which compares with bainite formed at elevated temperatures where the strain is $\approx 0.26$ [62]. This goes some way towards explaining why the plates are so thin since the strain energy per unit volume scales with the square of the shear strain [63]. The reason why the crystallography changes for the lower transformation temperatures involved is not established.

2. Deep studies with atomic resolution by Caballero and co-workers in particular [60, 64, 65], and others [58] have confirmed the presence of carbon at dislocations and boundaries, as postulated on the basis of early atom probe studies [49]. There is also some evidence of the presence of incredibly small carbides present in a structure which is often thought to be a mixture of just bainitic ferrite and retained austenite. Other observations such as the incomplete-reaction phenomenon and the configurational freezing of the substitutional solutes are all consistent with a vast body of previous research [66].

3. The most exciting discovery from the atomic resolution studies is definitive proof that the excess carbon in bainitic ferrite is not just found at defects, but is present in solid solution $[59,60]$. This is an insightful result which can only be explained by the displacive transformation mechanism.

4. In contradiction to studies of the hardness of retained austenite and bainitic ferrite in high-temperature bainite [67], the nanohardness of the thin bainite platelets in the nanostructured steel exceeds that of retained austenite [68]. The probable explanation is first the fine scale of the plates and second, the excess carbon that they contain, when compared against bainite generated at higher temperatures.

5. Since rapid cooling is unnecessary to generate the nanostructure, it has been suggested that residual stresses or the associated distortion due to heat-treatment should be minimal [21]. A recent study [69] confirms this for the nanostructured bainite, although the results are misinterpreted in terms stress relaxation in the retained austenite, whereas the observations are macroscopic and better explained in terms of the homogeneous temperature achieved by the steel prior to transformation. In terms of the mechanism of the phase change, it has been demonstrated that the transformation plasticity characteristic of displacive transformations and crystallographic variant selection occurs when the nanostructure is generated under the influence of an externally applied stress [70]. 
(a)

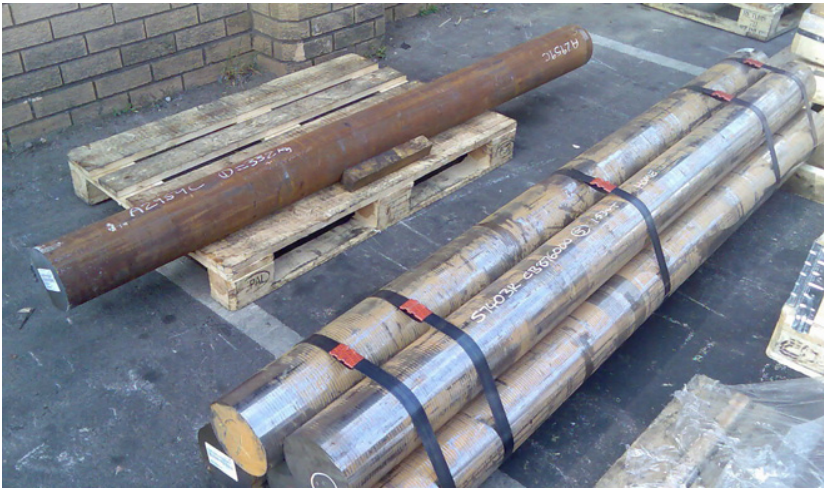

(b)

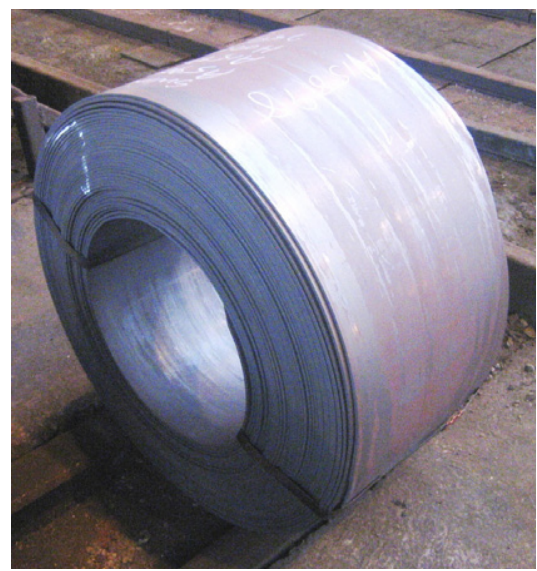

Figure 5. Large scale manufacture of nanostructured steel: (a) shafts and (b) plates. Photographs courtesy of Rolls Royce Plc and Tata Steel, respectively.

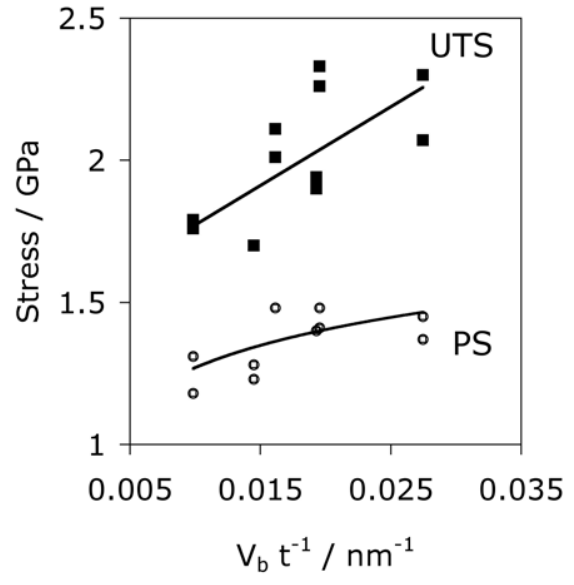

(a)

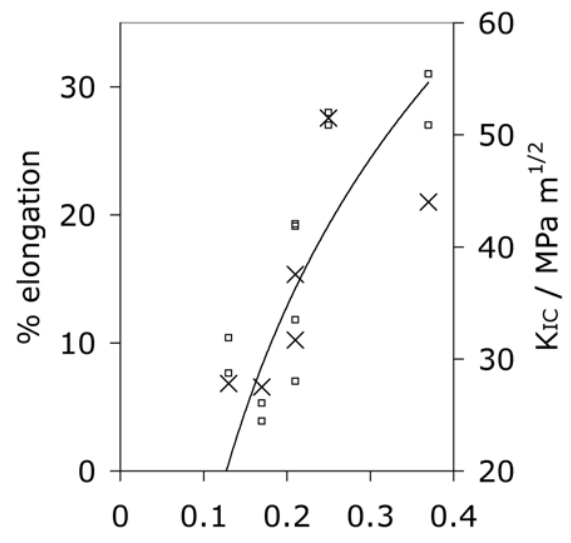

(b)

Figure 6. Some mechanical properties of two superbainitic steels [46]. (a) The ultimate tensile strength (UTS) and $0.2 \%$ proof strength as a function of the volume fraction of bainitic ferrite $\left(V_{b}\right)$ divided by the ferrite platelet thickness $t$. (b) Ductility (points and curve) and toughness $K_{\mathrm{IC}}$ are represented by crosses.

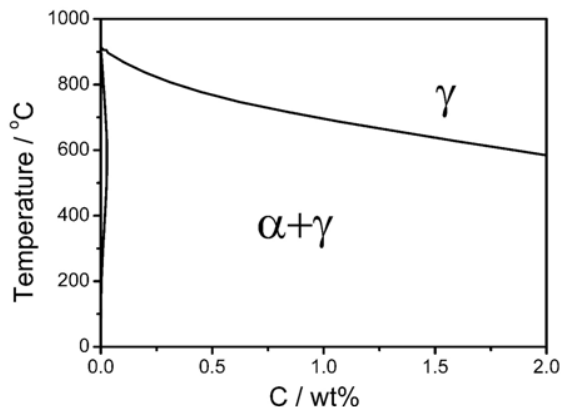

(a)

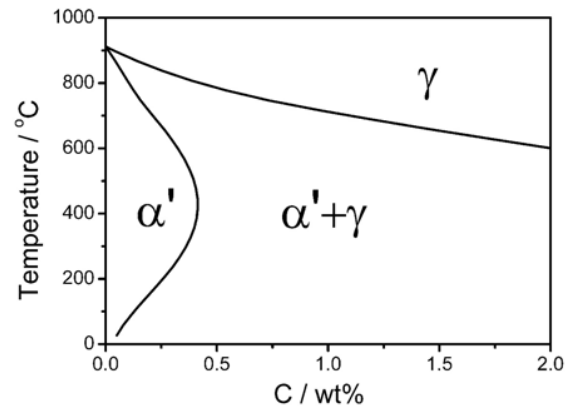

(b)

Figure 7. Binary phase diagram of the Fe-C system allowing (a) equilibrium between body-centred cubic ferrite and austenite, (b) between body-centred tetragonal ferrite and austenite [61].

\section{Welding}

The nanostructured bainite has been successfully commercialized but only for applications which do not require welding. This is because the class of steels which leads to the desired structure contains a high carbon concentration, a carbon equivalent in excess of 1 , which in normal circumstances would be considered unacceptable for welding.

Indeed, autogenous laser welding of a typical high-carbon bainitic steel $(\mathrm{Fe}-0.8 \mathrm{C}-1 \mathrm{Si}-1.5 \mathrm{Mn}-1.8 \mathrm{Al} \mathrm{wt} \%)$ has been shown to lead to dramatic cracking within the martensitic 


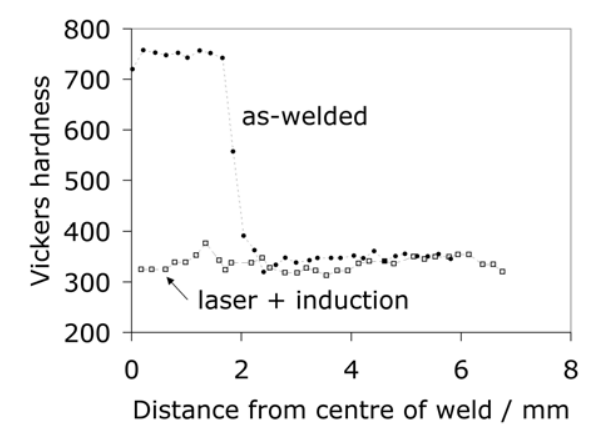

(a)

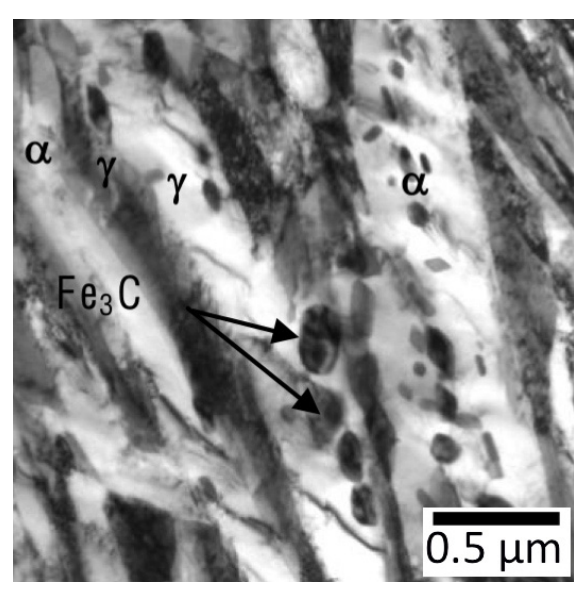

(b)

Figure 8. (a) Hardness profiles for both the as laser-welded and the combined laser and induction heated samples. (b) Bright field transmission electron micrograph showing the structure resulting from simulation of welding heat-affected zone using both laser and induction heating. Data from [71], micrograph courtesy of S G Hong.

weld nugget which has a hardness of $800 \mathrm{HV}$ [71]. However, it has been shown by experiment that by trailing an induction heating coil behind the moving laser beam, it is possible to avoid such cracks. The induction coil heats up the nugget at some $100^{\circ} \mathrm{C} \mathrm{s}^{-1}$ to a temperature of $800^{\circ} \mathrm{C}$, followed by cooling at $40^{\circ} \mathrm{C} \mathrm{s}^{-1}$, reducing the hardness to just $350 \mathrm{HV}$ and eliminating cracking. This would also explain the observed softening. The hardness variations from the centre of the weld are illustrated in figure $8(\mathrm{a})$.

It was argued in the original work [71] that the rapid heating leads to the displacive formation of austenite, but the evidence presented is weak. Consistent with microstructural and chemical information presented in the paper, it is likely that the partial transformation to austenite occurred by a reconstructive mechanism leading to a mixture of austenite $(\gamma)$, tempered bainite $(\alpha)$ and cementite during the heating stage (figure $8(\mathrm{~b})$ ).

The work by Hong and co-workers [71] deals with welding rather a soft bainite $(\approx 320 \mathrm{HV})$ generated by transformation at $400^{\circ} \mathrm{C}$. It does not therefore address potential problems associated with the heat-affected zone of welds when joining the strong, nanostructured bainite with a hardness of about $650 \mathrm{HV}$. A recent review [72] for the welding of strong bainite concludes that there are three issues to consider: (a) brittle martensite formation in both the fusion zone and the heat-affected zone in its close proximity; (b) the formation of cementite in the heat-affected zone further away from the weld, and (c) cold cracking in the weld itself. These issues have not yet been investigated in detail and there are no studies in the open literature which relate the changes in structure to engineering properties. This could in principle be a fertile field of study if an application is found for strong bainite which requires joining.

\section{Summary}

The world's first bulk nanostructured metal is now in production; its essence lies in detailed solid-state phase transformation theory, meticulously researched and argued over many decades. There is now a framework of knowledge which allows such materials to be developed systematically, beginning with calculations that define experiments.

The weakness of the nanostructured bainite is that it cannot at the moment be satisfactorily welded. This limits its applications to objects which do not require joining, such as armour, shafts and bearings. It would be good to focus technological research in this area to develop practical and cheap methods which might turn out to be generically helpful for strong steels.

It has not been possible in this short review to address the fact that combinations of properties need to be optimized in order for a steel concept to be successful. Strength alone is obviously not enough. It is worth in this context pointing out an exciting development where delamination is exploited to obtain remarkable fracture toughness at low temperatures [73].

\section{References}

[1] Cottrell A H 1993 Eur. Rev. 1169

[2] Christian J W 1975 Theory of Transformations in Metals and Alloys, Part I 2nd edn (Oxford: Pergamon)

[3] Bhadeshia H K D H 2001 Geometry of Crystals 2nd edn (Institute of Materials)

[4] Hall E O 1951 Proc. Phys. Soc. A 64747

[5] Petch N J 1953 J. Iron Steel Inst. 17425

[6] Naylor J P 1979 Metall. Trans. A 10861

[7] Daigne J, Guttmann M and Naylor J P 1982 Mater. Sci. Eng. 561

[8] Christian J W 1982 Metall. Trans. A 13509

[9] Gerberich W W, Thomas G, Parker E R and Zackay V F 1970 2nd Int. Conf. on Strength of Metals and Alloys (Ohio: ASM International) p 894

[10] Speich G R, Cuddy L J, Gordon C R and DeArdo A J 1984 Phase Transformations in Ferrous Alloys ed A R Marder and J I Goldstein (Warrendale, PA: TMS-AIME) p 341

[11] Nishioka K and Ichikawa K 2012 Sci. Technol. Adv. Mater. 13023001

[12] Yokota T, Garcia-Mateo C and Bhadeshia H K D H 2004 Scr. Mater. 51767 
[13] Garcia-Mateo C, Caballero F G and Bhadeshia H K D H 2003 ISIJ Int. 431238

[14] Kimura Y, Hidaka H and Takaki S 1999 Mater. Trans. JIM 401149

[15] Timokhina I, Beladi H, Xiong X Y, Adachi Y and Hodsgon P 2011 Solid State Phenom. 172-174 1249

[16] Isheim D, Gagliano M S, Fine M E and Seidman D N 2006 Acta Mater. 54841

[17] Tsuji N, Saito Y, Utsunomiya H and Tanigawa S 1999 Scr. Mater. 40795

[18] Valiev R Z, Ivanisenko Y V, Rauch E F and Baudelet B 1996 Acta Mater. $\mathbf{4 4} 4705$

[19] Wang Y, Ma E, Valiev R Z and Zhu Y 2004 Adv. Mater. 16328

[20] Bhadeshia H K D H 2010 Proc. R. Soc. Lond. A 4663

[21] Bhadeshia H K D H 2005 Mater. Sci. Technol. 211293

[22] Peet M and Bhadeshia H K D H 2011 Metall. Mater. Trans. A 423344

[23] Singh S B and Bhadeshia H K D H 1998 Mater. Sci. Eng. A A245 72

[24] Hu F and Wu K 2011 Adv. Mater. Res. 146-147 1843

[25] Bhadeshia H K D H 1999 Mater. Sci. Eng. A 273-275 58

[26] Kaufman L and Cohen M 1958 Prog. Metal Phys. 7165

[27] Bhadeshia H K D H 1981 Acta Metall. 291117

[28] Ghosh G and Olson G B 2001 J. Phase Equilib. 22199

[29] Bhadeshia H K D H 1982 Metal Sci. 16159

[30] Caballero F G, Bhadeshia H K D H, Mawella K J A, Jones D G and Brown P 2002 Mater. Sci Technol. 18279

[31] Garcia-Mateo C, Caballero F G and Bhadeshia H K D H 2003 J. Physique Coll. 112285

[32] Howe A A 2000 Mater. Sci. Technol. 161264

[33] Howe A A 2009 Mater. Sci. Technol 25815

[34] Caballero F G and Bhadeshia H K D H 2004 Curr. Opin. Solid State Mater. Sci. 8251

[35] The Secretary of State for Defence, Bhadeshia H K D H and Brown P 2010 (Patent Number GB2462197, Intellectual Property Office, London)

[36] Garcia-Mateo C, Caballero F G and Bhadeshia H K D H 2005 Mater. Sci. Forum 500-501 495

[37] Garcia-Mateo C, Caballero F G, Sourmail T, Kuntz M, Cornide J, Smanio V and Elvira E 2012 Mater. Sci. Eng. A 549185

[38] Hasan H S 2012 Eng. Technol. J. 302165

[39] Hamdeny A 2010 Mechanical property modelling of steels PhD Thesis University of Technology, Bhagdad (www.msm.cam.ac.uk/phase-trans/2011/Aseel_Thesis.pdf)

[40] Yoozbashi M N, Yazdani S and Wang T S 2011 Mater. Des. 323248

[41] Peet M J, Hill P, Rawson M, Wood S and Bhadeshia H K D H 2011 Mater. Sci. Technol. 27119

[42] Zhang P, Zhang F C, Yan Z G, Wang T S and Qian L H 2011 Mater. Sci. Forum 675-677 585

[43] Zhang P, Zhang F C, Yan Z G, Wang T S and Qian L H 2011 Wear 271697

[44] Yang J, Wang T S, Zhang B and Zhang F C 2012 Wear 282-283 81

[45] Lonardelli I, Bortolotti M, van Beek W, Girardini L, Zadra M and Bhadeshia H K D H 2012 Mater. Sci. Eng. A 555139
[46] Garcia-Mateo C and Caballero F G 2005 Mater. Trans. 461839

[47] Aaronson H I, Domian H A and Pound G M 1966 TMS-AIME 236753

[48] Bhadeshia H K D H 1982 Metal Sci. 16167

[49] Bhadeshia H K D H and Waugh A R 1982 Acta Metall. 30775

[50] Bhadeshia H K D H and Waugh A R 1982 Solid-Solid Phase Transformations ed H I Aaronson, D E Laughlin, R F Sekerka and C M Wayman (Warrendale, PA: TMS-AIME) 993

[51] Stark I, Smith G D W and Bhadeshia H K D H 1988 Phase Transformations '87 ed G E Lorimer (London: Institute of Metals) p 211

[52] Stark I, Smith G D W and Bhadeshia H K D H 1990 Metall. Trans. A 21837

[53] Bhadeshia H K D H 1988 Phase Transformations '87 ed G W Lorimer (London: Institute of Metals) p 309

[54] Peet M, Babu S S, Miller M K and Bhadeshia H K D H 2004 Scr. Mater. $\mathbf{5 0} 1277$

[55] Caballero F G, Miller M K, Babu S S and Garcia-Mateo C 2007 Acta Mater. 55381

[56] Garcia-Mateo C, Peet M, Caballero F G and Bhadeshia H K D H 2004 Mater. Sci. Technol. 20814

[57] Caballero F G, Miller M K, Clarke A J and Garcia-Mateo C 2010 Scr. Mater. 63442

[58] Timokhina I B, Xiong X Y, Beladi H, Mukherjee S and Hodgson P D 2011 Mater. Sci. Technol. 27739

[59] Caballero F G, Miller M K, Garcia-Mateo C and Cornide J 2012 J. Alloys Compounds (doi:10.1016/j.jallcom.2012.02.130)

[60] Caballero F G, Miller M K, Garcia-Mateo C, Cornide J and Santofimia M J 2012 Scr. Mater. 67846

[61] Jang J H, Bhadeshia H K D H and Suh D W 2012 Scr. Mater. 68195

[62] Swallow E and Bhadeshia H K D H 1996 Mater. Sci. Technol. 12121

[63] Christian J W 1958 Acta Metall. 6377

[64] Caballero F G, Miller M K and Garcia-Mateo C 2010 Mater. Sci. Technol. 26 889-898

[65] Caballero F G, Miller M K and Garcia-Mateo C 2011 Solid State Phenom. 172-174 111-116

[66] Bhadeshia H K D H 2001 Bainite in Steels 2nd edn (London: Institute of Materials)

[67] Furnemont Q, Kempf M, Jacques P J, Göken M and Delannay F 2002 Mater. Sci. Eng. A 328A 26-32

[68] Lan H F, Liu X H and Du L X 2011 Adv. Mater. Res. 156-157 1708

[69] Amey C M, Huang H and del Castillo P E J R D 2012 Mater. Des. $\mathbf{3 5} 66$

[70] Kundu S, Hase K and Bhadeshia H K D H 2007 Proc. R. Soc. Lond. A 4632309

[71] Hong S G, Cho M H and Lee J S 2010 63rd Annual Assembly and Int. Conf. of the International Institute of Welding vol AWST-10/99 (France: International Institute of Welding) p 47

[72] Fang K, Yang J, Zhao D, Song K, Yan Z and Fang H 2012 Adv. Mater. Res. 482-484 2405

[73] Inoue T, Kimura Y and Ochiai S 2012 Sci. Technol. Adv. Mater. 13035005 